\title{
The model for deliverability of gas well with complex shape sand bodies and small-scale reserve of Sulige Gas Field in China
}

\author{
Wenge $\mathrm{Hu} \cdot$ Xiangfang $\mathrm{Li} \cdot$ Keliu Wu$\cdot$ \\ Mingyou Yu $\cdot$ Gang Wang $\cdot$ Pengpeng Song
}

Received: 1 December 2013/Accepted: 5 August 2014/Published online: 21 August 2014

(C) The Author(s) 2014. This article is published with open access at Springerlink.com

\begin{abstract}
Because of the complex shape sand bodies of Sulige Gas Field, gas well controlled reserves is low, and reservoir pressure drop fast, it is very hard to accurately forecast gas well deliverability. Based on the study of characteristics of sand bodies, four superimposed sand models and a two-region seepage model are put forward. Using the material balance method of natural water drive gas reservoir and cumulative production methods to calculate dynamic reserve of near wellbore I and distant wellbore II and cumulative gas invaded volume from distant wellbore II. Boundary reservoir pressure was calculated by the iteration in different production periods, and the deliverability model was established based on gas deliverability equation of pseudo-stationary flow in gas well of complex shape sand bodies and small-scale reserve in Sulige Gas Field. The model considers not only distribution characteristics of reservoir pressure in different seepage modes, but also fast dropping of reservoir pressure. The application shows that the result is accurate, the mean error being below $10 \%$ and the model can meet the requirement of the project.
\end{abstract}

Keywords Sulige Gas Field · Gas well deliverability . Dynamic reserve $\cdot$ Material balance method $\cdot$ Reservoir pressure

W. Hu $\cdot$ X. Li $\cdot$ K. Wu $(\bowtie)$

Key Laboratory for Petroleum Engineering of the Ministry of Education, China University of Petroleum, Beijing 102249,

China

e-mail: wukeliu19850109@163.com

M. Yu · G. Wang $\cdot$ P. Song

Daqing Oilfield, China National Petroleum Corporation (CNPC),

Daqing 163412, China

\section{List of symbols}

$G_{1} \quad$ Controlled reserve of near wellbore area $\mathrm{I}, 10^{4} \mathrm{~m}^{3}$

$G_{\mathrm{p}} \quad$ The accumulative gas production of gas well, $10^{4} \mathrm{~m}^{3}$

$G_{\mathrm{c}} \quad$ The accumulative gas supply from distant wellbore area II to near wellbore area $\mathrm{I}, 10^{4} \mathrm{~m}^{3}$

$B_{\mathrm{g} 1} \quad$ Gas volume factor of current reservoir pressure $p_{1}$ of near wellbore area I, dimensionless

$B_{\mathrm{g} 1 \mathrm{i}} \quad$ Gas volume factor of initial reservoir pressure $p_{1 \mathrm{i}}$ of near wellbore area I, dimensionless

$C_{\mathrm{f} 1} \quad$ Rock compressibility coefficient of near wellbore area I, dimensionless

$C_{\mathrm{w} 1}$ Bound water compressibility coefficient of near wellbore area I, dimensionless

$S_{\mathrm{w} 1 \mathrm{i}}$ saturation of bound water of near wellbore area I, dimensionless

a Coefficient, dimensionless

$b \quad$ Coefficient, dimensionless

$c \quad$ Constant, dimensionless

$t \quad$ Gas well production time, month

$p \quad$ Current reservoir pressure, $\mathrm{MPa}$

$p_{\mathrm{i}} \quad$ Initial reservoir pressure, $\mathrm{MPa}$

$z \quad$ Gas deviation factor at current reservoir pressure $p$, dimensionless

$z_{\mathrm{i}} \quad$ Gas deviation factor at initial reservoir pressure $p_{i}$, dimensionless

$p_{\mathrm{pc}} \quad$ Pressure at standard conditions, MPa

$T \quad$ Current gas reservoir temperature, $\mathrm{K}$

$T_{\mathrm{pc}} \quad$ Temperature at standard conditions, $\mathrm{K}$

$p_{\mathrm{pr}} \quad$ Contrastive pressure of gas reservoir, dimensionless

$T_{\mathrm{pr}}$ Contrastive temperature of gas reservoir, dimensionless

$\gamma \quad$ Gas relative density, dimensionless

$\rho_{\mathrm{R}} \quad$ Contrastive density of natural gas

$p_{\mathrm{wf}} \quad$ Bottom hole flowing pressure, MPa

$Q_{\mathrm{sc}} \quad$ Gas production rate, $10^{4} \mathrm{~m}^{3} /$ day 
A Coefficient, dimensionless

$B \quad$ Coefficient, dimensionless

\section{Introduction}

The calculation of gas well deliverability is the major part of gas reservoir development and management (Yin et al. 2007). With the development of gas reservoir, reservoir pressure lowers, gas well deliverability changes and the correspondent deliverability equation changes (Yang et al. 2007; Hao and Wang 2000). The deliverability testing shows physical property of peripheral gas reservoir and the mean reservoir pressure have obvious effects on gas well deliverability and absolute open flow (He and Hao 2001; Gou 2005). Because of the various factors, especially lowpermeability gas reservoir, gas flow state is not stable in short period process of deliverability testing. In other words, the gas production rate and bottom hole flowing pressure are measured before pressure waves spread to the outer formation boundary and this cannot reflect the physical property of peripheral reservoir, thus deliverability curves are abnormal and cannot be applied ( $\mathrm{Li}$ and $\mathrm{Li}$ 2004).

Because sand-body shape of Sulige Gas Field is complex, single well controlled reserve is low, and reservoir pressure drops fast, so it is very hard to accurately forecast gas well deliverability. Based on the special mining model and field data, Li et al. (2007) used regression method to put forward the empirical equation of gas well deliverability, which could only be used in early production period ( $\mathrm{Li}$ et al. 2007). Based on the unique reservoir characteristics of Sulige Gas Field, we consider the reservoir pressure distribution of different seepage region and the fast dropping of reservoir pressure, derive and finally establish gas well deliverability model suitable for Sulige Gas Field at any production period.

\section{The characteristics of sand-body morphology and seepage models}

The characteristics of sand-body morphology

Sulige Gas Field is situated in North Sulige, Erdos basin. The proved gas reserves are $6,000 \times 10^{8} \mathrm{~m}^{3}$ in Permian system Shanxi $\mathrm{fm}$ and Xiashihezi $\mathrm{fm}$. The eighth layer of Shihezi fm, the delta deposit of braised river, is the main reservoir and the effective reservoirs mainly grow in the distributary channel of delta plain (Yang et al. 2007). Sand isopachous map and sedimentary facies map show that effective sand bodies are mainly in isolated distribution. Based on the research results such as dense well anatomy, exposure and deposit simulation, the sand-body stretching range of $800-1,200 \mathrm{~m}$ is obtained, with a few being over $1,200 \mathrm{~m}$, length-width ratio being $2 \sim 3$ and shape being oval or long oval ( $\mathrm{Li}$ et al. 2009).

Sand-body superposition models of Sulige Gas Field are mainly isolated model, incision superposition model, accumulative superposition model and horizontally partconnecting model, as shown in Fig. 1.

Seepage models

The sand-body scale of Sulige Gas Field is small, so when pressure spreads to the width boundary it does not obey the seepage rules of pure radical flow, as shown in Fig. 2. Take oval isolated sand bodies for example, seepage regions are divided into two types.

1. In the early production period, it is radical flow in the near well area before pressure waves reach sand-body width boundary.

2. In the middle and late production periods, it is unidirectional flow in the distant wellbore area after pressure waves reach sand-body width boundary.

The unique reservoir characteristics of Sulige Gas Field lead to different seepage models in different regions and thus the characteristics of pressure falling are different. The effect on fluid flow is as effective as that of the differences of reservoir property on fluid flow.

\section{The model of gas well deliverability}

Determining dynamic reserves

The sand-body shape of Sulige Gas Field is complex and single well controlled reserve is small. Reservoir pressure drops fast when there is a producing well in the middle area, and the pattern of gas seepage of whole reservoir should be divided into two regions. For example, the isolated sand body can be divided into the radical flow region of near wellbore area I and the unidirectional flow region of distant wellbore area II. According to material balance principle, the following equation can be derived:

$$
\begin{aligned}
G_{1} B_{\mathrm{g} 1 \mathrm{i}}= & \left(G_{1}-G_{\mathrm{p}}\right) B_{\mathrm{g} 1}+G_{1} B_{\mathrm{g} 1 \mathrm{i}}\left(\frac{C_{\mathrm{w} 1} S_{\mathrm{w} 1 \mathrm{i}}+C_{\mathrm{f} 1}}{1-S_{\mathrm{w} 1 \mathrm{i}}}\right) \\
& +G_{\mathrm{c}} B_{\mathrm{g} 1}
\end{aligned}
$$

For the low-pressure characteristics of Sulige Gas Field, the elastic expansion of bound water and rock can be neglected, then Eq. (1) simplifies to: 
Fig. 1 Schematic diagram of sand-body superposition models of Sulige Gas Field

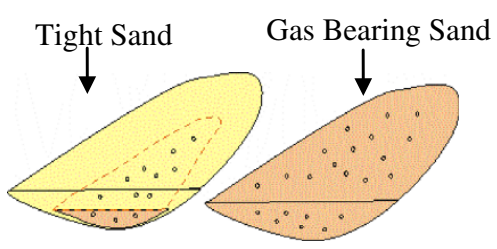

Isolated Model

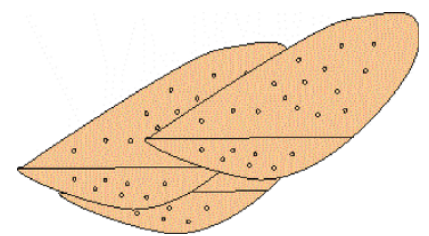

Incision Superposition Model

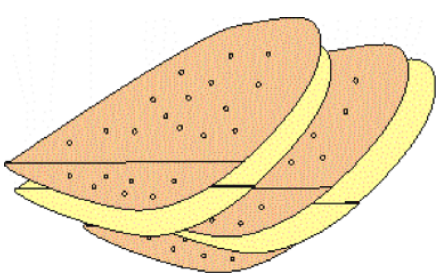

Accumulative Superposition Model

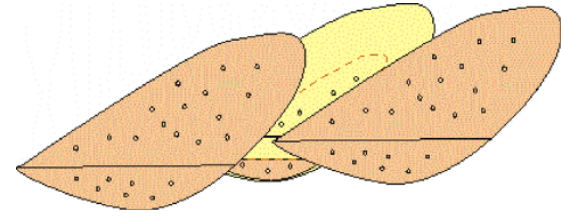

Horizontally Part-Connecting Model

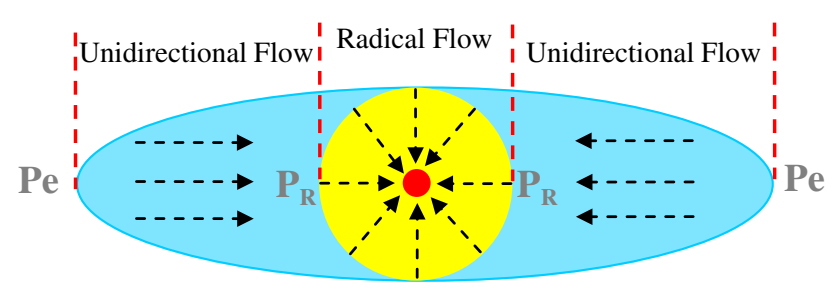

Fig. 2 Schematic diagrams of isolated sand-body seepage models

$G_{\mathrm{p}} B_{\mathrm{g} 1}=G_{1}\left(B_{\mathrm{g} 1}-B_{\mathrm{g} 1 \mathrm{i}}\right)+G_{\mathrm{c}} B_{\mathrm{g} 1}$

Equation (2) can be considered as material balance equation of complex shape sand-body gas reservoir with gas supply under the two regions sewage pattern. $G_{\mathrm{c}}$ is the accumulative gas supply from distant wellbore area II to near wellbore area I, which is called gas invaded volume.

Referencing the method of using material balance equation of natural water drive gas reservoir to calculate gas reserve and water influx volume, Eq. (2) becomes deformed as

$\frac{G_{\mathrm{p}} B_{\mathrm{g} 1}}{B_{\mathrm{g} 1}-B_{\mathrm{g} 1 \mathrm{i}}}=G_{1}+\frac{G_{\mathrm{c}} B_{\mathrm{g} 1}}{B_{\mathrm{g} 1}-B_{\mathrm{g} 1 \mathrm{i}}}$

where we used $y$ for convenience:

$y=\frac{G_{\mathrm{p}} B_{\mathrm{g} 1}}{B_{\mathrm{g} 1}-B_{\mathrm{g} 1 \mathrm{i}}}$

Analyzing Eq. (3), $y$ on the left of the equation represents accumulative gas production, the first term on the right represents initial gas reserve of near wellbore area I and the second term reflects the recharge capacity of distant wellbore area II, which is related to gas reserve, sand-body shape characteristics, reservoir physical property and fluid property of distant wellbore area II (Wang et al. 2004).

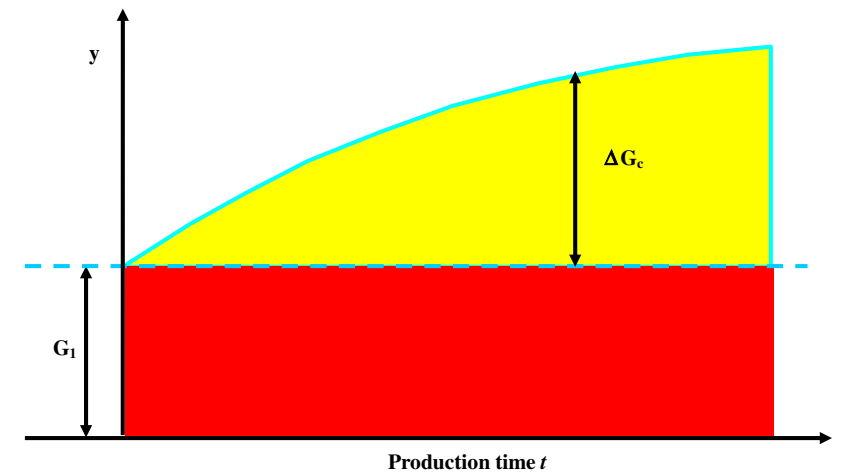

Fig. 3 Schematic diagram of accumulative gas production of different production periods

The accumulative gas production $\left(G_{\mathrm{p}}\right)$ and gas invaded volume $\left(G_{\mathrm{c}}\right)$ are related to production time $t$. According to Eq. (3), a relation curve of accumulative gas production (y) and production time $t$ can be drawn. According to Fig. 3, the intercept of y axis is controlled reserve $G_{1}$ of near wellbore area I; the differences between y value of different periods and controlled reserve horizontal level of near wellbore area I reflect the gas supply from distant wellbore area III to near wellbore area I, which is gas invaded volume $\left(G_{\mathrm{c}}\right)$.

According to Eq. (3), and combined with Fig. 3, we can get gas invaded volume of different periods from distant wellbore area II to near wellbore area I.

$G_{\mathrm{c}}=\left(\frac{B_{\mathrm{g} 1}-B_{\mathrm{g} 1 \mathrm{i}}}{B_{\mathrm{g} 1}}\right) \Delta G_{\mathrm{c}}=\left(\frac{B_{\mathrm{g} 1}-B_{\mathrm{g} 1 \mathrm{i}}}{B_{\mathrm{g} 1}}\right)\left(y-G_{1}\right)$

Regarding near wellbore area I as an expansive well, the gas invaded volume of different periods can be considered as the accumulative gas production of expansive well. So dynamic reserve of distant wellbore area II can be 
calculated by using accumulative production method as follows: (Wang 1997):

$G_{\mathrm{c}}=a-\frac{b}{t+c}$,

where $a$ and $b$ are the coefficients and $c$ is the constant.

Based on Eq. (6), when $t \rightarrow \infty, b /(t+c) \rightarrow 0, G_{\mathrm{c}}=a$, $a$ is the dynamic reserve $\left(G_{2}\right)$ of distant wellbore area II, and the dynamic reserve of whole gas reservoir $G=G_{1}+G_{2}$ can be calculated by this time.

\section{Getting reservoir pressure}

For constant volume natural gas reservoir, its material balance equation is:

$\frac{p}{z}=\frac{p_{\mathrm{i}}}{z_{\mathrm{i}}}\left(1-\frac{G_{\mathrm{p}}}{G}\right)$

The gas deviation factor $z$ can be calculated by using Standing-Katz plate that Dranchuk and Abou-Kassem fitted in 1974.

$$
\left\{\begin{aligned}
z= & 1+\left(0.31506-\frac{1.0467}{T_{\mathrm{pr}}}-\frac{0.5783}{T_{\mathrm{pr}}^{3}}\right) \rho_{R} \\
& +\left(0.5353-\frac{0.6123}{T_{\mathrm{pr}}}-\frac{0.6815}{T_{\mathrm{pr}}^{3}}\right) \rho_{\mathrm{R}}^{2} \\
p_{\mathrm{pr}} & =\frac{p}{p_{\mathrm{pc}}} \\
T_{\mathrm{pr}} & =\frac{T}{T_{\mathrm{pc}}} \\
T_{\mathrm{pc}} & =171(\gamma-0.5)+182 \\
p_{\mathrm{pc}} & =[46.7-32.1(\gamma-0.5)] \times 0.09869
\end{aligned}\right.
$$

The contrastive density of natural gas $\rho_{\mathrm{R}}$ is:

$\rho_{\mathrm{R}}=\frac{0.27 p_{\mathrm{pr}}}{z T_{\mathrm{pr}}}$

$\gamma$ is gas relative density.

By combining Eq. (7) with (9) and using iteration, reservoir pressure $p$ of any time can be calculated, as shown in Fig. 4.

When accumulative gas production is $G_{\mathrm{p}}$, supposed reservoir pressure is $p$, assign a small value to $p$ (i.e., $p=0.1$ ) and the initial value to corresponding $z$ (i.e., $\left.z_{0}=1\right), \rho_{\mathrm{R}}$ is obtained from Eq. (9). Substitute $\rho_{\mathrm{R}}$ into Eq. (8), a new $z$ is got, and use new $z$ to replace the initial value, repeat this process until the difference of two results is less than a certain minimum allowance. In this way, the left value $p / z$ of Eq. (7) is obtained, compared with the right value of Eq. (7). If the difference is too big, then let $p=p+0.001$, recalculate the corresponding $z$ until the difference between $p / z$ and the right value of Eq. (7) is

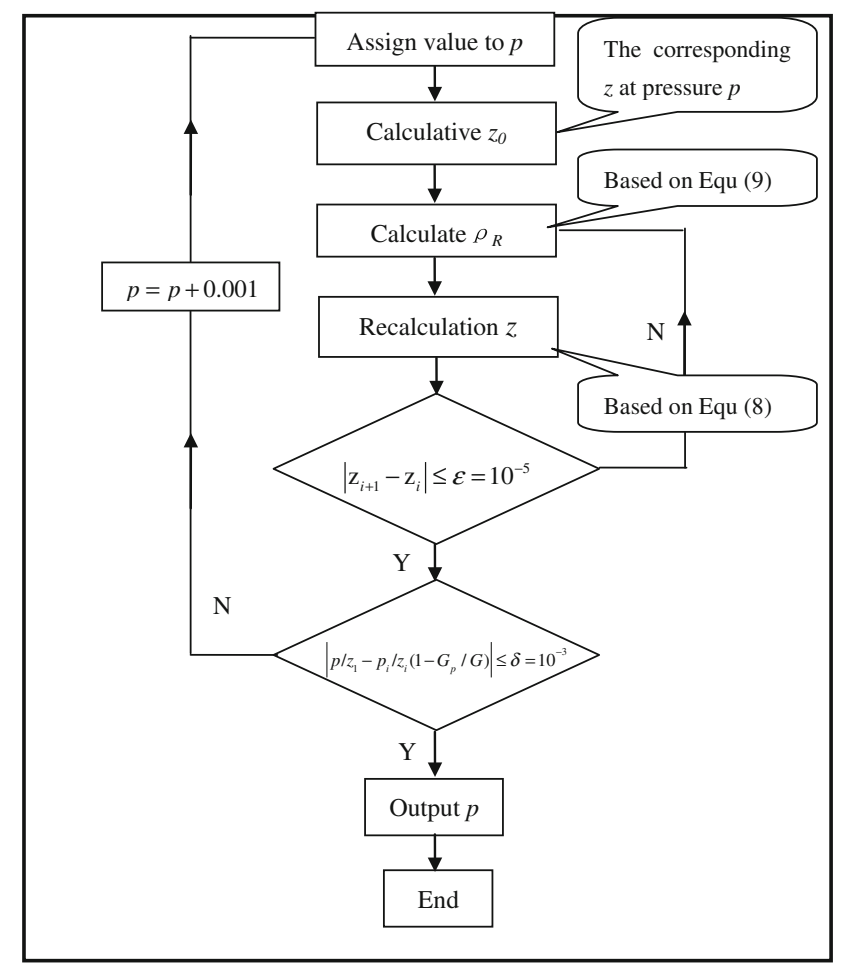

Fig. 4 The flow chart for calculating $P$

small enough. (that is, $\left|p / z_{1}-p_{\mathrm{i}} / z_{\mathrm{i}} \quad\left(1-G_{\mathrm{p}} / G\right)\right|$ $\left.\leq \delta=10^{-3}\right)$. At last, the right reservoir pressure is obtained.

Deliverability calculation of gas well

Gas deliverability equation of pseudo-steady-state flow (Li 2008)

$p^{2}-p_{\mathrm{wf}}^{2}=A Q_{\mathrm{sc}}+B Q_{\mathrm{sc}}^{2}$

The sand-body shape of Sulige Gas Field is complex, the controlled reserve of single well is small and reservoir pressure drops fast. In order to calculate the gas well deliverability accurately, reservoir pressure of any production time in deliverability equation should choose the reservoir pressure of distant wellbore area II. The computational process is the same as "Getting reservoir pressure", then the corresponding dynamic reserve $G$ and the accumulative gas production $G_{\mathrm{p}}$ in Eq. (7) are substituted by $G_{2}$ and $G_{\mathrm{c}}$, respectively.

Based on material balance equation, the pseudo-pressure $p / z$ of small reserve gas well drops fast, and it reflects that the reservoir pressure drops fast, as shown in Fig. 5.

For complex sand-body shape and small reserve gas well of Sulige Gas Field, the deliverability drops when the reservoir pressure drops. In other words, reservoir pressure and deliverability drops fast when gas recovery is continuously increased, as shown in Fig. 6. 


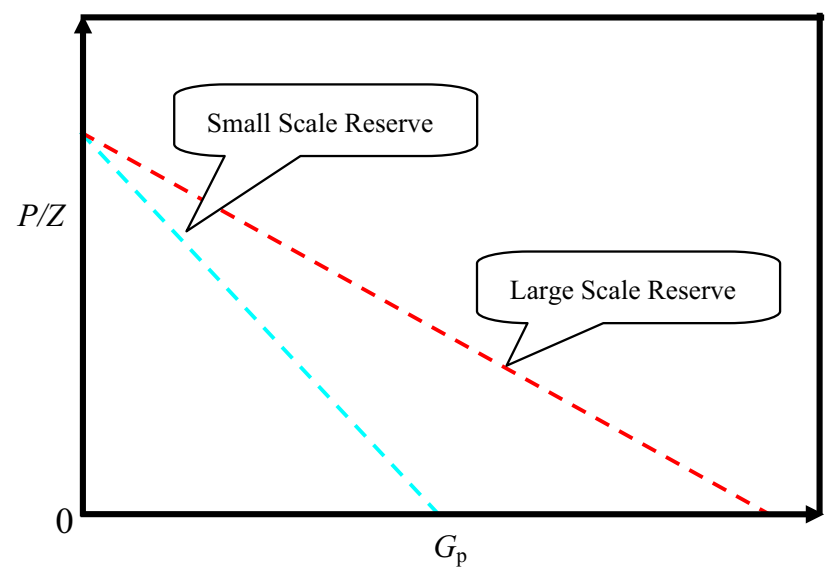

Fig. 5 Schematic diagram of the relation between pseudo-pressure and accumulative production

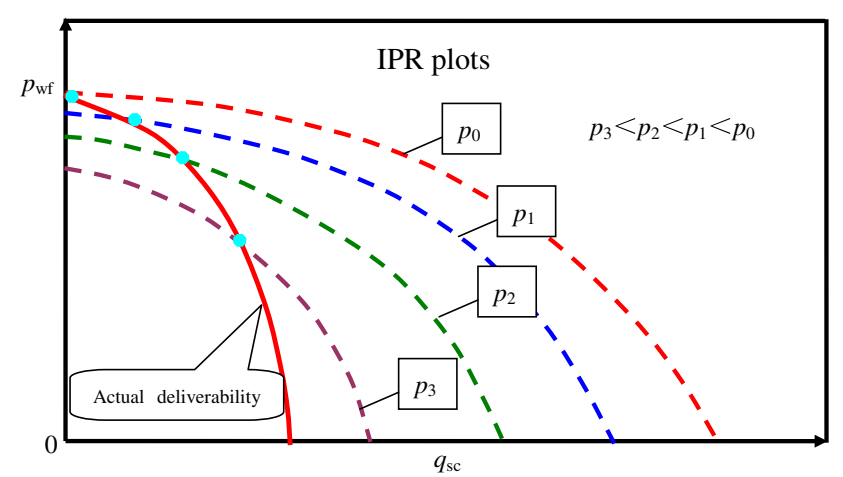

Fig. 6 Schematic diagram of gas well deliverability of low-reserve gas reservoir

\section{Case calculations}

It is a certain production well of Sulige Gas Field. The reservoir has isolated sand bodies, the effective sand bodies being $850 \mathrm{~m}$ long, length width ratio being 2.5 and the shape being oval. The pay section is layer $\mathrm{H} 8_{\mathrm{L}} 4$ of Shihezi, effective porosity $\varphi$ is $8.95 \%$, effective permeability $k$ is $0.73 \times 10^{-3} \mu \mathrm{m}^{2}$ and original reservoir pressure $p_{i}$ is 27.61 MPa. The gas well production data are shown in Fig. 7.

According to "Determining dynamic reserves", $G_{1}$, the dynamic reserve of near wellbore area $I$ is $1,613.8 \times 10^{4} \mathrm{~m}^{3}$ and $G_{2}$, the dynamic reserve of distant wellbore area II is $873.7 \times 10^{4} \mathrm{~m}^{3}$ and $G$, the total reserve is $2,487.5 \times 10^{4} \mathrm{~m}^{3}$ which is classified as a low-reserve reservoir. Up till March 31, 2010 the accumulative invading gas of distant wellbore area II towards near wellbore area $\mathrm{I}$ is $307.3 \times 10^{4} \mathrm{~m}^{3}$, as shown in Figs. 8, 9 and 10 .

According to "Getting reservoir pressure", calculate $p_{\mathrm{e}}$, the mean reservoir pressure of distant wellbore area II and $p_{\mathrm{R}}$, the mean pressure of whole reservoir, as shown in Fig. 11. Reservoir pressure drops from 27.61 MPa in Nov. 21, 2007 to $17.11 \mathrm{MPa}$ in Mar. 20th, 2010. $p_{\mathrm{e}}$, the mean reservoir pressure of distant wellbore area II is higher than $p_{\mathrm{R}}$, the mean pressure of the whole reservoir by 0.11-3.75 MPa

Based on calculated reservoir pressure and the respective gas well deliverability of "Deliverability calculation of gas well", results are shown in Figs. 1, 2, Tables 1, 2. Model I is the deliverability Model after $p_{\mathrm{e}}$ is substituted to Eq. (10). Model II is the deliverability Model after $p_{\mathrm{R}}$ is
Fig. 7 The production data curves of a certain production well of Sulige Gas Field

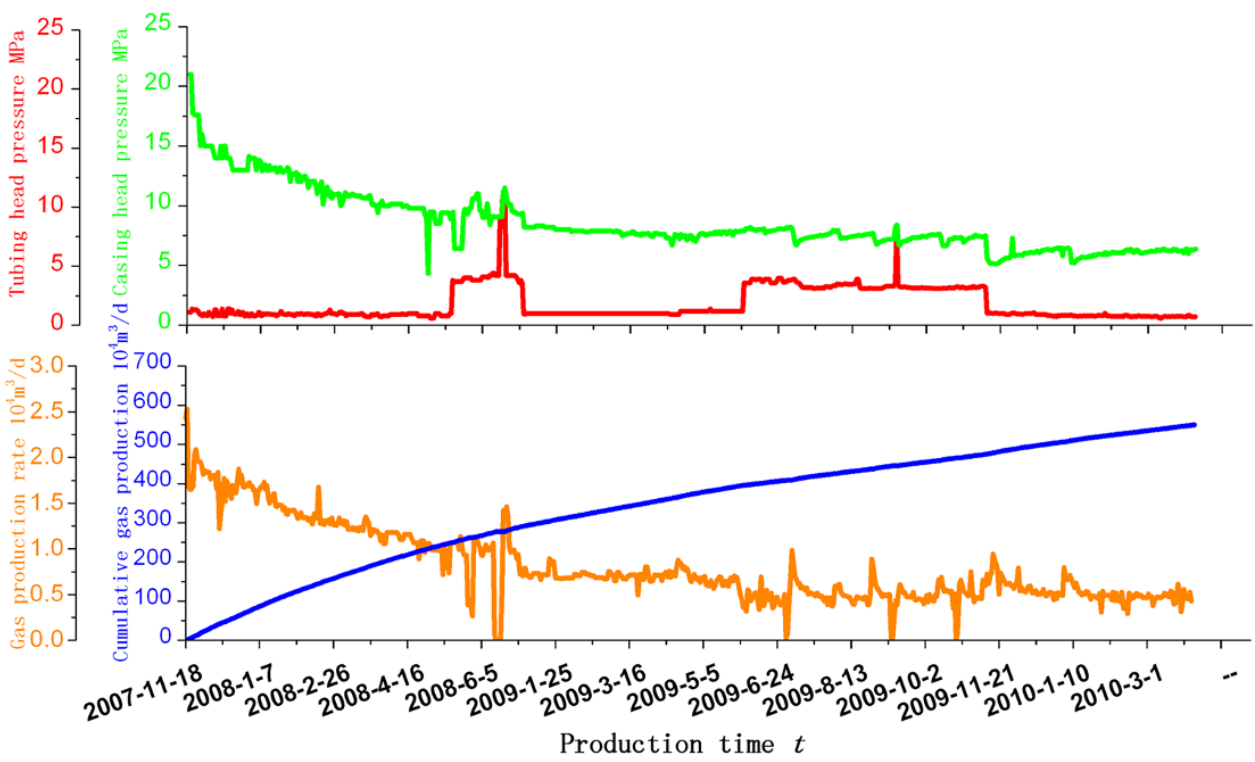




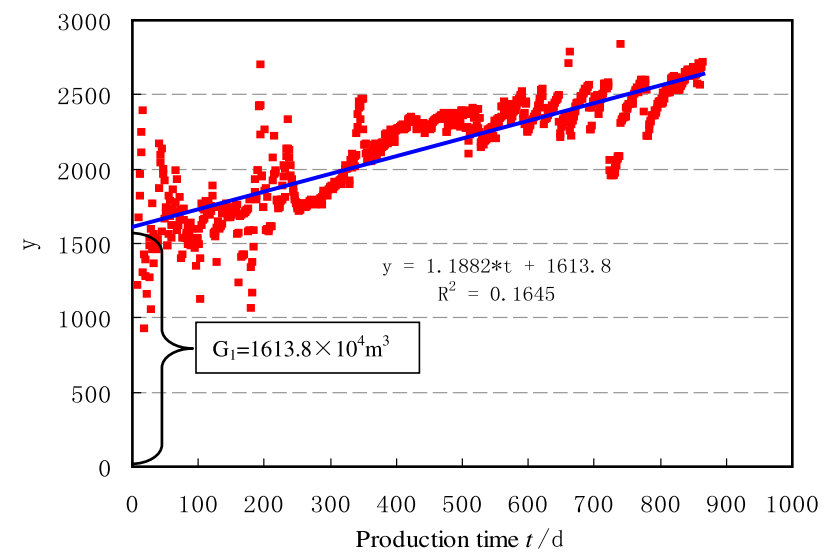

Fig. 8 The relation curves of accumulative gas production and production time

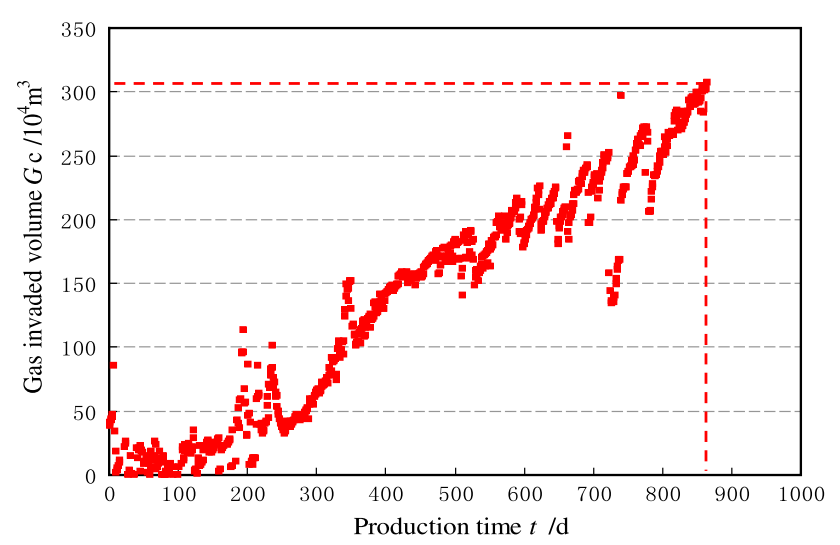

Fig. 9 The gas invaded volume of distant wellbore area II towards near wellbore area I

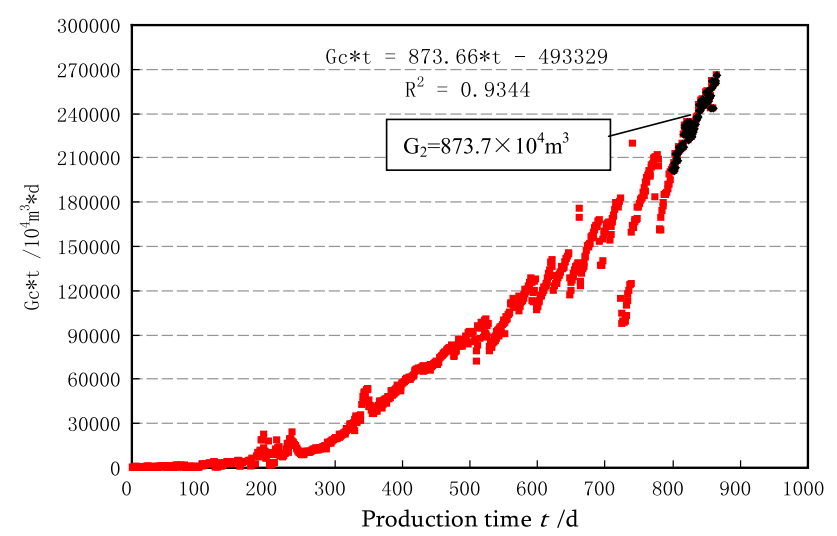

Fig. 10 Dynamic reserve curves of distant wellbore area II with accumulative production

substituted. Model III and Model IV are, respectively, the deliverability Models after original $p_{\mathrm{e}}$ and original $p_{\mathrm{R}}$ are substituted. They are all constant, in other words, those have not considered reservoir pressure is changing in especially low-reserve gas reservoir.
Figure 12 shows reservoir pressure drops fast with production time and the IPR curve differences of Model I and II are bigger and bigger $\left(d_{1}<d_{2}<d_{3}<d_{4}\right)$. In the middle and late production periods, the gas invaded volume of distant wellbore area II decreases and the near wellbore area I continuously produces gas, approaching deficit, so reservoir pressure of near wellbore area I drops fast. The mean reservoir pressure based on distant wellbore area II is more close to current boundary reservoir pressure of whole reservoir.

Tables 1 and 2 show that, Model $\mathrm{I}$ is the most accurate, with an error being below $10 \%$, followed by Model II and Model IV. Model III has the biggest error of $904 \%$. Model I considers not only distribution characteristics of reservoir pressure under different seepage region, with reservoir pressure of distant wellbore area II more close to actual boundary reservoir pressure, but also fast dropping of reservoir pressure of low-reserve gas reservoir, so that calculative gas deliverability is more close to actual gas production rate. Model III and Model IV have not considered the low controlled reserve of single well and the fast dropping of reservoir pressure and simply hold that the reservoir pressure is invariant (always the reservoir pressure in Jan. 5th, 2008). Compared with Model IV, in Model III the differences between the early mean reservoir pressure of distant wellbore area and actual reservoir pressure are bigger, the deliverability errors are bigger.

\section{Conclusions}

1. The new method to calculate dynamic reserve of complex sand bodies of Sulige Gas Field is established. Using material balance method of natural water drive gas reservoir and accumulative production methods to, respectively, calculate dynamic reserves of near wellbore area I and distant wellbore area II and the gas invaded volume from distant wellbore area II to near wellbore area I.

2. The method to calculate boundary reservoir pressure of low-reserve gas reservoir of complex sand bodies of Sulige Gas Field in different production periods is derived. With material balance method, the mean reservoir pressure of distant wellbore area II is calculated based on the dynamic reserve of distant wellbore area II and gas invaded volume, and it accurately reflects reservoir pressure of whole gas reservoir.

3. It establishes the model on gas deliverability of complex sand bodies and small-scale reserve of Sulige Gas Field. The model comprehensively considers the distribution characteristics of reservoir pressure under different seepage region and fast dropping of reservoir pressure of small-scale reserve gas reservoir. 
Fig. 11 The changing curves of reservoir pressure

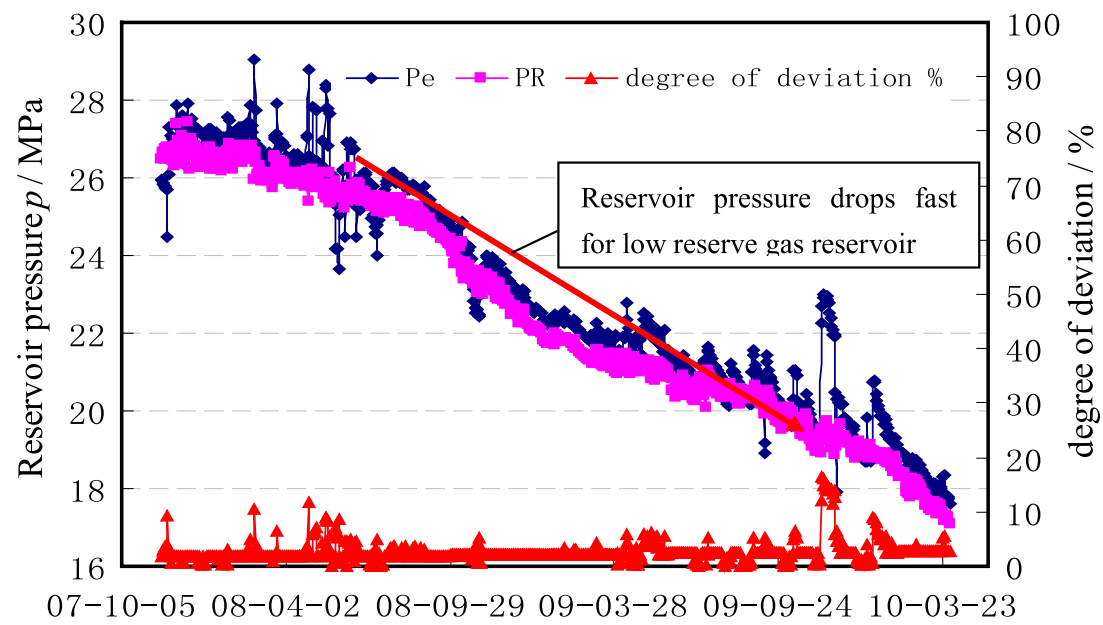

Production time $t / \mathrm{d}$

Table 1 The comparison between actual production and calculative production under different models

\begin{tabular}{llllll}
\hline$Q_{\text {sc }} / 10^{4} \mathrm{~m}^{3}$ & Model I & Model II & Model III & Model IV & Actual \\
\hline $2008-1-5$ & 1.4789 & 1.2971 & 1.4789 & 1.2971 & 1.4930 \\
$2008-10-2$ & 1.0108 & 0.7852 & 2.1468 & 1.9666 & 0.9910 \\
$2009-6-16$ & 0.5953 & 0.2349 & 3.5849 & 3.4080 & 0.5457 \\
$2010-3-28$ & 0.5222 & 0.0399 & 4.9459 & 4.7540 & 0.4925 \\
\hline
\end{tabular}

Table 2 The comparison of calculative production errors under different models

\begin{tabular}{lllccr}
\hline Error/\% & Model I & Model II & Model III & Model IV & / \\
\hline $2008-1-5$ & 0.95 & 13.12 & 0.95 & 13.12 & / \\
$2008-10-2$ & 2.00 & 20.77 & 116.64 & 98.45 & / \\
$2009-6-16$ & 9.10 & 56.96 & 556.94 & 524.52 & / \\
$2010-3-28$ & 6.03 & 91.89 & 904.24 & 865.28 & / \\
\hline
\end{tabular}

4. The application of a certain gas well of Sulige Gas Field shows that Model I is the most accurate, with an error of being below $10 \%$, which are followed by Model II and Model IV. Model III has the biggest error of $904 \%$. Model I considers not only the distribution characteristics of reservoir pressure under different seepage region, with reservoir pressure of distant wellbore area II more close to actual boundary reservoir pressure, but also fast dropping of reservoir pressure of low-reserve gas reservoir. Model III and Model IV have not considered the low single well controlled reserve and the fast dropping of reservoir pressure and simply hold that reservoir pressure is invariant. Compared with Model IV, in Model III the differences between the early mean reservoir pressure of distant wellbore area and actual reservoir pressure are bigger, the deliverability errors are bigger.

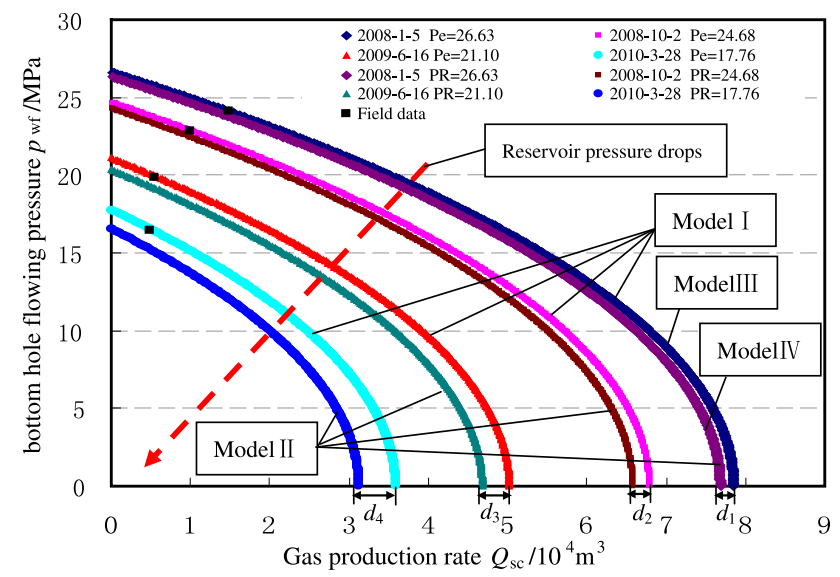

Fig. 12 IPR curves of different deliverability models

Acknowledgments This paper was sponsored by National Key Basic Research Program (973 Program) (2007CB209506). We recognize the support of MOE Key Laboratory of Petroleum Engineering in China University of Petroleum (Beijing) for the permission to publish this paper.

Open Access This article is distributed under the terms of the Creative Commons Attribution License which permits any use, distribution, and reproduction in any medium, provided the original author(s) and the source are credited.

\section{References}

Dranchuk PM, Abou-Kassem JH (1974) Calculation of z-factors for natural gases using equation of state. JCPT 14(3):34-35

Gou SQ (2005) Effects of heterogeneity on productivity testing of gas wells. Nat Gas Ind 25(3):109-112

Hao YH, Wang FY (2000) Influence of formation pressure decrease on the productivity equation and open flow capacity of gas well. Nat Gas Ind 20(1):71-74

He ZX, Hao YH (2001) Analysis of effects of permeability on gas well productivity equation and open flow capacity. Pet Explor Dev 28(5):46-48 
Li SL (2008) Gas reservoir engineering (Edition 2). Petroleum Industry Press, Beijing

Li XP, Li Y (2004) A new way to analyze productivity of gas wells. Nat Gas Ind 24(2):76-78

Li JQ, Yang ZL, Ji YC, Chen QW (2007) Method to calculate the gas well production capacity under special mining patterns of Sulige gas field. Nat Gas Ind 27(12):105-107

Li LZ, Li XF, He DB, Shi JT, Li G (2009) Establishment of the deliverability equation of elliptic isolated sandbody in Sulige gas field. Nat Gas Ind 29(4):71-73

Wang MH (1997) Gas reservoir engineering. Petroleum Industry Press, Beijing
Wang WH, Shen PP, Ma XH, Fan LH, Tang JW (2004) Verification of dynamic reserves for heterogeneous complex gas reservoirs with low permeability. Nat Gas Ind 24(7):80-82

Yang JH, He FZ, Zou YH (2007a) A study on dynamic productivity calculation for gas wells using data from pressure transient testing. Nat Gas Ind 27(3):95-96

Yang XP, Zhao WZ, Zou CN, Li W, Tao SZ (2007b) Comparison of formation conditions of "sweet point" reservoirs in Sulige gas field and Xiangxi group gas field in the central Sichuan basin. Nat Gas Ind 27(1):4-7

Yin L, Huang QH, Zhan ML et al (2007) Stress sensitive effect on gas well productivity. J Southwest Pet Univ 29(11):46-49 